\title{
Rain-on-snow events over North America based on two Canadian regional climate models
}

\author{
Dae II Jeong ${ }^{1} \cdot$ Laxmi Sushama $^{1}$
}

Received: 29 July 2016 / Accepted: 27 February 2017 / Published online: 10 March 2017

(c) The Author(s) 2017. This article is published with open access at Springerlink.com

\begin{abstract}
This study evaluates projected changes to rainon-snow (ROS) characteristics (i.e., frequency, rainfall amount, and runoff) for the future 2041-2070 period with respect to the current 1976-2005 period over North America using six simulations, based on two Canadian RCMs, driven by two driving GCMs for RCP4.5 and 8.5 emission pathways. Prior to assessing projected changes, the two RCMs are evaluated by comparing ERA-Interim driven RCM simulations with available observations, and results indicate that both models reproduce reasonably well the observed spatial patterns of ROS event frequency and other related features. Analysis of current and future simulations suggest general increases in ROS characteristics during the November-March period for most regions of Canada and for northwestern US for the future period, due to an increase in the rainfall frequency with warmer air temperatures in future. Future ROS runoff is often projected to increase more than future ROS rainfall amounts, particularly for northeastern North America, during snowmelt months, as ROS events usually accelerate snowmelt. The simulations show that ROS event is a primary flood generating mechanism over most of Canada and north-western and -central US for the January-May period for the current period and this is projected to continue in the future period. More focused analysis over selected basins shows decreases in future spring runoff due to decreases in both snow cover and ROS runoff. The above results highlight the need to
\end{abstract}

Dae Il Jeong

jeong@sca.uqam.ca

1 Centre ESCER (Étude et Simulation du Climat à l'Échelle Régionale), Université du Québec à Montréal, 201, Ave. President-Kenned, Montreal, QC H2X 3Y7, Canada take into consideration ROS events in water resources management adaptation strategies for future climate.

Keywords Climate change $\cdot$ Flood $\cdot$ North America . Rain-on-snow events $\cdot$ Regional climate modeling

\section{Introduction}

Rain-on-snow (ROS) events have a complex generation mechanism and are dependent on air temperature and associated precipitation types (rain or snow) as well as the areal extent and thickness of the snowpack (McCabe et al. 2007; Freudiger et al. 2014). Warmer air temperatures in future climate can decrease ROS frequency by reducing snowfall and days with snow cover on the ground in mid-latitude regions (McCabe et al. 2007). However, an increase in ROS frequency, due to increasing rainfall days, can be expected in high-latitude and mountainous regions, where, despite the increase in temperatures, snow cover is present during most of the winter months as air temperatures are generally below freezing point for these regions (Ye et al. 2008). Therefore, it is very important to evaluate how these events will evolve in a future warming climate at regional scale. ROS events have significant impacts on various sectors such as the cold region environment and ecosystem (Putkonen and Roe 2003; Putkonen et al. 2009; Rennert et al. 2009; Casson et al. 2010) and water resources, particularly for flood forecasting and risk management (Leathers et al. 1998; Sui and Koehler 2001; McCabe et al. 2007; Pradhanang et al. 2013; Surfleet and Tullos 2013; Freudiger et al. 2014).

Based on observed datasets, several studies investigated ROS events and their changes due to rising air temperatures. For instance, due to increases in temperature 
and decreases in snow cover days, a general decrease in the October-May ROS days was detected for low elevation sites in the western United States for the 1969-2003 period by McCabe et al. (2007). A positive correlation of ROS days with elevation and a negative correlation with increasing air temperatures for New York State, US, for the 2004-2012 period were reported by Pradhanang et al. (2013). Winters with higher maximum temperatures had more ROS events than cooler winters due to more rainfall occurrences, for the case of south-central Ontario, Canada, for the 1971-2001 period (Casson et al. 2010). Similarly, an increase in winter ROS events with warmer air temperatures for the northern Eurasian high-latitude regions was reported for the 1936-1990 period (Ye et al. 2008). These increased ROS frequency and associated snowmelt in winter could have direct influence on decreased spring snow water equivalent (SWE) and spring water storage and supply in snowmelt-dominated regions (Jeong et al. 2016c).

Limited studies have focused on projected changes to ROS events in future climate based on General Circulation Models (GCMs). A 40\% increase in the winter ROS area has been projected for the northern part (north of $45^{\circ} \mathrm{N}$ ) of the northern hemisphere by 2080-2089 period based on the geophysical fluid dynamics laboratory (GFDL) GCM for a standard anthropogenic climate forcing scenario of a $1 \%$ per year increase in $\mathrm{CO}_{2}$ (Putkonen and Roe 2003). An increase in the frequency and the areal extent of winter ROS events for many parts of the Arctic for the 2040-2059 period were projected based on the community climate system model 3 (CCSM3) outputs for the special report on emissions scenarios (SRES) A2 scenario of the intergovernmental panel on climate change (IPCC 2001) (Rennert et al. 2009). Regional climate models (RCMs) are commonly used to add details to GCM simulations and to investigate climate change impacts at regional scales (e.g., Diro et al. 2014; Jeong et al. 2014a, b, 2016a, 2016b). However, detailed regional-scale studies of projected changes to ROS events in future climate are not yet available for most parts of the world, including the North American continent.

Impacts of ROS events on floods have been investigated in several studies (e.g., Leathers et al. 1998; Sui and Koehler 2001; Pradhanang et al. 2013; Freudiger et al. 2014; Nied et al. 2014) using observed datasets, as these events can produce severe floods during snow-melt seasons, especially when the soil is frozen and the snowpack amount is abnormal (Marks et al. 1998; Floyd and Weiler 2008). However, these impacts have been rarely investigated for future climate scenarios. Based on a hydrologic model driven by eight statistically downscaled GCM simulations for the SRES A1B and B1 scenarios, a decrease in the frequency of high peak flows driven by ROS events for low and middle elevation zones, and an increase for high elevation areas were reported for future climate, for the mountainous river basins of Oregon, United States (Surfleet and Tullous 2013). Moreover, the impact of ROS event changes on the annual water cycle, due to changes in runoff induced by these events, has been rarely studied over North America, based on both observations and projected future datasets.

Therefore, our main objective is to evaluate projected changes to selected ROS event characteristics for the future 2041-2070 period, with respect to the current 1976-2005 period, for the North American landmass, using six simulations based on two Canadian RCMs, driven by two driving GCMs, for two representative concentration pathways (RCP) scenarios. The mechanisms of future ROS events are investigated by evaluating changes to relevant climate variables such as precipitation types and their frequency and intensity, snowpack amount and extent, as well as the $2 \mathrm{~m}$ air temperature from the six RCM simulations. Projected changes to the maximum daily runoff and water balance, induced by the changes in future ROS events, are also evaluated over North America, based on the RCM simulations.

\section{Models and datasets}

\subsection{RCMs and their simulations}

The fifth-generation Canadian Regional Climate Model (CRCM5) developed by the Centre pour 1'Étude et la Simulation du Climat à l'Échelle Régionale (ESCER Centre) at the University of Québec at Montréal (UQAM) and the CanRCM4 developed by the Canadian Centre for Climate Modelling and Analysis division of the Climate Research Branch of Environment and Climate Change Canada $(\mathrm{CCCma} / \mathrm{ECCC})$ are used in this study. Both RCMs are based on the global environmental multiscale (GEM) model (Côté et al. 1998) and thus have the same dynamics. The physical parameterizations in CRCM5 are similar to those in GEM, except for the land surface and the radiation schemes. CanRCM4 uses the same parameterizations as in the forth-generation Canadian Atmospheric global climate model, CanAM4 (von Salzen et al. 2013). The main characteristics and physical parameterizations (e.g., radiation scheme, boundary layer scheme, orographic gravity wave drag, aerosol scheme, grid-scale microphysics, convection schemes, land-surface scheme, land use, soil initialization and so on) of the two RCMs have been compared in detail by Whan and Zwiers (2016), but a brief description is given here.

CRCM5 uses the Kain and Fritsch (1992) deep-convection scheme and the Bélair et al. (2005) shallow-convection scheme. The resolvable large-scale precipitation is modeled by following Sundqvist et al. (1989), while radiation is parameterized by Correlated $\mathrm{K}$ solar and terrestrial 
radiation of $\mathrm{Li}$ and Barker (2005). This model uses the interactive Flake lake model (Martynov et al. 2012) and Canadian Land Surface Scheme (CLASS) 3.5 (Verseghy 2009, 2012) for the land part. CLASS 3.5 allows flexible soil layer configuration and employs prognostic equations for energy and water conservation for the soil layers and a thermally and hydrologically distinct snow pack (Diro et al. 2014).

CanRCM4 uses the deep-convection scheme of Zhang and McFarlane (1995) and the shallow-convection scheme parameterized following von Salzen and McFarlane (2002) and von Salzen et al. (2005). The correlated K distribution method ( $\mathrm{Li}$ and Barker 2005) is employed for the absorption by gases in the atmosphere while the Monte Carlo Independent Column Approximation (McICA; Barker et al. 2008; Pincus et al. 2003) is adopted for radiative transfers. The land surface scheme in CanRCM4 is an earlier version of CLASS (i.e., CLASS 2.7) with three soil layers of thickness $0.10,0.25$, and $3.75 \mathrm{~m}$.

In CRCM5, four precipitation types (i.e., snow, ice pellets, freezing rain, and rain) or mixtures of these types are diagnosed following Bourgouin (2000). The vertical temperature profile is the main determinant of the precipitation types. Detailed procedure can be found in Bourgouin (2000). However, at the land surface, CRCM5 considers only two types, i.e., snow and rain. Even if the precipitation type obtained by the Bourgouin approach is freezing rain or ice pellets, it is treated as rain at the land surface. CanRCM4 has only two precipitation types - snow and rain.

The simulations considered in this study cover whole of North America and adjoining oceans at $0.44^{\circ}$ resolution. The atmospheric lateral boundary conditions are obtained from the European Centre for Medium-Range Weather Forecasts (ECMWF) gridded ERA-Interim reanalysis dataset (Dee et al. 2011), the CCCma Canadian Earth System Model 2 (CanESM2) simulated dataset (Arora et al. 2011), and the Max-Planck-Institut Earth System Model (MPI-ESM) simulated data (Giorgetta et al. 2013). CRCM5 and CanRCM4 simulations driven by the ERA-Interim reanalysis (CRCM5-ERA and CanRCM4-ERA hereafter) for the 1989-2008 period are used for the evaluation of the RCMs. The two CRCM5 simulations driven by CanESM 2 and MPI-ESM and one CanRCM4 simulation driven by CanESM2 considered in this study, for the current 1976-2005 period, are referred to as CRCM5-CanHist, CRCM5-MPIHist, and CanRCM4CanHist, respectively. These simulations, when compared to their reference ERA-driven simulations, can give errors due to the errors in the driving data. Four CRCM5 simulations driven by CanESM2 and MPI-ESM and two CanRCM4 simulations driven by CanESM2, for the RCP4.5 and RCP8.5 pathways, are used for the 2041-2070 future period. These simulations are named
CRCM5-CanRCP4.5, CRCM5-CanRCP8.5, CRCM5MPIRCP4.5, CRCM5-MPIRCP8.5, CanRCM4-CanRCP4.5, and CanRCM4-CanRCP8.5, based on the RCM, boundary forcing dataset, and emission pathway considered. These simulations are compared to the respective current period simulations to quantify projected changes. It is important to note that MPI-driven simulations for CanRCM4 were not available. Table 1 provides a summary of all simulations considered in this study.

\subsection{Observed datasets}

For validation purposes, gridded observations of daily precipitation from Maurer et al. (2002) for the United States and from Hutchinson et al. (2009) and Hopkinson et al. (2011) for Canada for the 1976-2010 period are used. The dataset from Maurer et al. (2002) is available at $0.125^{\circ}$ resolution and cover the contiguous United States. This precipitation dataset was constructed based on observations from the National Oceanic and Atmospheric Administration (NOAA) Cooperative observer program (COOP) stations (Maurer et al. 2002). The Hopkinson et al. (2011) precipitation dataset covers the Canadian landmass south of $60^{\circ} \mathrm{N}$ at a spatial resolution of $0.1^{\circ}$. This Canadian dataset was developed from daily observations from Environment Canada's climate stations, using a thin plate smoothing spline surface fitting method (Hutchinson et al. 2009). The gridded daily SWE used for validation is that from Brown et al. (2003), available at $0.3^{\circ}$ resolution, for the 1979-1996 period.

Table 1 Summary of RCM simulations considered in this study

\begin{tabular}{lllll}
\hline Name & RCM & Driving data & Period & Scenario \\
\hline CRCM5-ERA & CRCM5 & ERA-Interim & $1989-2008$ & - \\
CRCM5-MPI- & & MPI-ESM & $1976-2005$ & Historical \\
Hist & & & & \\
CRCM5-CanHist & & CanESM2 & $1976-2005$ & Historical \\
CRCM5- & & MPI-ESM & $2041-2070$ & RCP4.5 \\
MPIRCP4.5 & & & & \\
CRCM5- & & MPI-ESM & $2041-2070$ & RCP8.5 \\
MPIRCP8.5 & & & & \\
CRCM5-Can- & & CanESM2 & $2041-2070$ & RCP4.5 \\
RCP4.5 & & & & \\
CRCM5-Can- & & CanESM2 & $2041-2070$ & RCP8.5 \\
RCP8.5 & & & & \\
CanRCM4-ERA & CanRCM4 & ERA-Interim & $1989-2008$ & - \\
CanRCM4- & & CanESM2 & $1976-2005$ & Historical \\
CanHist & & & & \\
CanRCM4- & & CanESM2 & $2041-2070$ & RCP4.5 \\
CanRCP4.5 & & & & \\
CanRCM4- & & CanESM2 & $2041-2070$ & RCP8.5 \\
CanRCP8.5 & & & & \\
\hline
\end{tabular}


The gridded daily precipitation and SWE datasets are up-scaled to the $0.44^{\circ}$ CRCM5 grid, using the nearest neighbour approach. It must be noted that there could be some uncertainties in the validation of ROS frequency, given that the original grids for precipitation and SWE are different, from which the observed ROS frequency is extracted after up-scaling to $0.44^{\circ}$. ROS frequency in ERA-Interim and CRCM5-ERA are also compared to assess added value of downscaling.

\section{Methodology}

For the ERA-Interim and RCM simulations, a ROS day is defined as a day with both liquid precipitation and SWE above $1 \mathrm{~mm}$, for a given grid cell, and the associated total rainfall and runoff, are referred to as ROS amount and runoff, respectively. As different types of precipitation are not available from observed gridded precipitation datasets, an observed ROS day is defined when both precipitation and SWE are above $1 \mathrm{~mm}$, and SWE decreases (which indicates snowmelt triggered by the rainfall event) following the definition of McCabe et al. (2007) and Surfleet and Tullos (2013). ROS amount and runoff are not evaluated as gridded observation datasets for different types of precipitation (solid vs. liquid) and runoff are not available.

Prior to the investigation of future projections, the ability of the RCMs in simulating ROS events are evaluated by comparing the spatial patterns of ROS days in CRCM5ERA and CanRCM4-ERA with those observed. The two RCMs are further evaluated by assessing their ability in simulating two ROS event related floods - the flood of April 2008 that occurred in the St-John River basin, located in the New Brunswick and Quebec provinces of Canada (Environment Canada 2008) and the March 2009 flood over the Red River basin, located in the North Dakota and Minnesota states of the United States and the Manitoba province of Canada (Environment Canada 2009). The climate variables such as air temperature, SWE, rainfall, and runoff, which are directly related to ROS events and floods, are verified for the two flood events in the ERA-Interim driven simulations of the two RCMs.

Projected changes to the ROS characteristics and their changing dynamics are investigated for North America using the 12 future simulations and their corresponding three current simulations. Projected changes to the maximum daily runoff and cumulative total runoff caused by ROS events for the spring months are then investigated for entire North America and two selected mountainous regions of western US, using the RCM simulations. Additionally, projected changes to surface water balance components such as precipitation, rainfall, SWE, and total runoff are compared with projected changes to ROS runoff for the St-John River and Red River basins, on a monthly time scale, to evaluate the influence of changes in ROS events on the future water balance at basin scale.

\section{Results}

\subsection{Evaluation}

Figure 1 shows the spatial distribution of monthly means of observed, reanalyzed (ERA-Interim), and modelled (CRCM5-ERA and CanRCM4-ERA) ROS days for selected months (Sep, Nov, Jan, Mar, May, and Jul) for the 1989-1996 period. This period is chosen as it is the common period when both precipitation and SWE data are available. The spatial patterns of the observed ROS days vary from 1 month to the other with changes in the surface air temperature. The observed ROS events are mostly concentrated in the coastal regions of Canada in November. These regions migrate further south in January and then move back north during the snowmelt period, following the freezing line. The two RCM simulations capture reasonably well the spatial distributions of the observed ROS days; however, they tend to overestimate the observed frequency, particularly over the central parts of North America. This difference could be due to the slight differences in the criteria used to identify ROS events from observed and simulated data as well as the different sources and resolutions of the observed daily precipitation and SWE. The boundary forcing errors, i.e. the errors stemming from the errors in the driving data, which are reflected in the differences between RCM simulations driven by GCMs and ERA-Interim reanalysis, are generally modest (not shown), compared to the performance errors, i.e., the errors associated with the physics and dynamics of the RCMs (Fig. 1). ERA-Interim exhibits slightly larger values over western and central parts of North America for the ROS frequency for November-March compared to the observation and two RCMs, indicating added value in downscaling ERAInterim reanalysis with CRCM5 for these regions.

The ability of the RCMs in simulating selected flood periods and related hydrometeorological features that triggered the flooding is investigated now. ROS events triggered severe floods in the St-John River basin during April 2008 (Environment Canada 2008) and in the Red River basin during March 2009 (Environment Canada 2009). Anomalously high snow on the ground, a sudden increase of temperature, and occurrence of rain led to rapid snowmelt, triggering the St-John River flood (Environment Canada 2008). Although higher than normal SWE was present in the Red River basin, the rapid snowmelt due to heavy ROS event was the main factor that contributed to the flooding in this basin. In Fig. 2, anomalies of ROS 


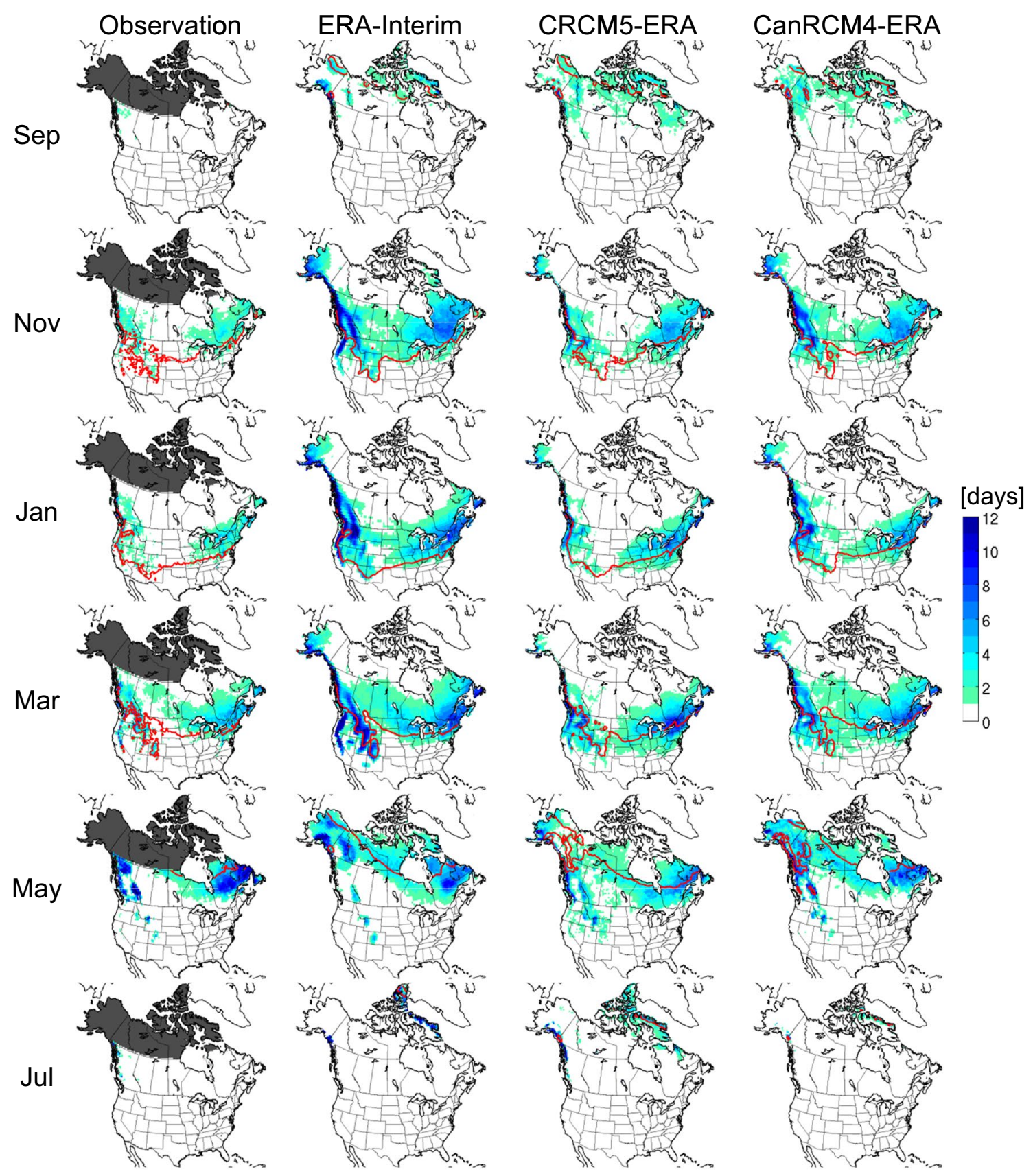

Fig. 1 Monthly means of ROS days for the 1989-1996 period from observation, ERA-Interim, CRCM5-ERA and CanRCM4-ERA. The red contour represents the mean freezing line, while the gray shading shows regions where observations are not available

characteristics, SWE, and ratio of ROS runoff for total runoff are presented over and around the two river basins during the flood months. In addition, spatially averaged daily time series of Tmax, SWE, and ROS amount and runoff for the two river basins, along with their climatology are shown for the affected years. The two RCM simulations (CRCM5-ERA and CanRCM4-ERA) display above-normal SWE and ROS runoff for the St-John River basin for the month of April. The ratio of ROS runoff to total runoff is also above normal, suggesting the high contribution of ROS runoff during the month of April. Moreover, the daily time series demonstrate that the two RCMs capture well the hydrometeorological features that led to the high ROS runoff during the month of April, i.e. significantly abovenormal SWE, sudden increase in Tmax, occurrence of several ROS events, and rapid snowmelt. For the Red River basin, the two RCM simulations show above-normal ROS runoff but exhibit different anomaly patterns for the 


\section{(a) Location of the St-John and Red River basins}

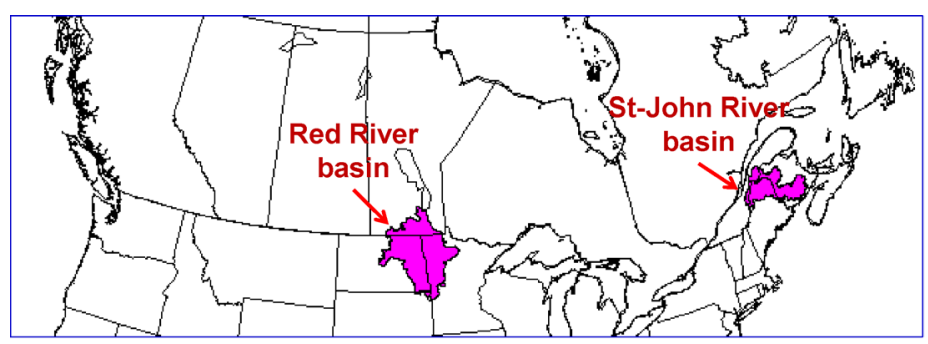

(b) St-John River basin

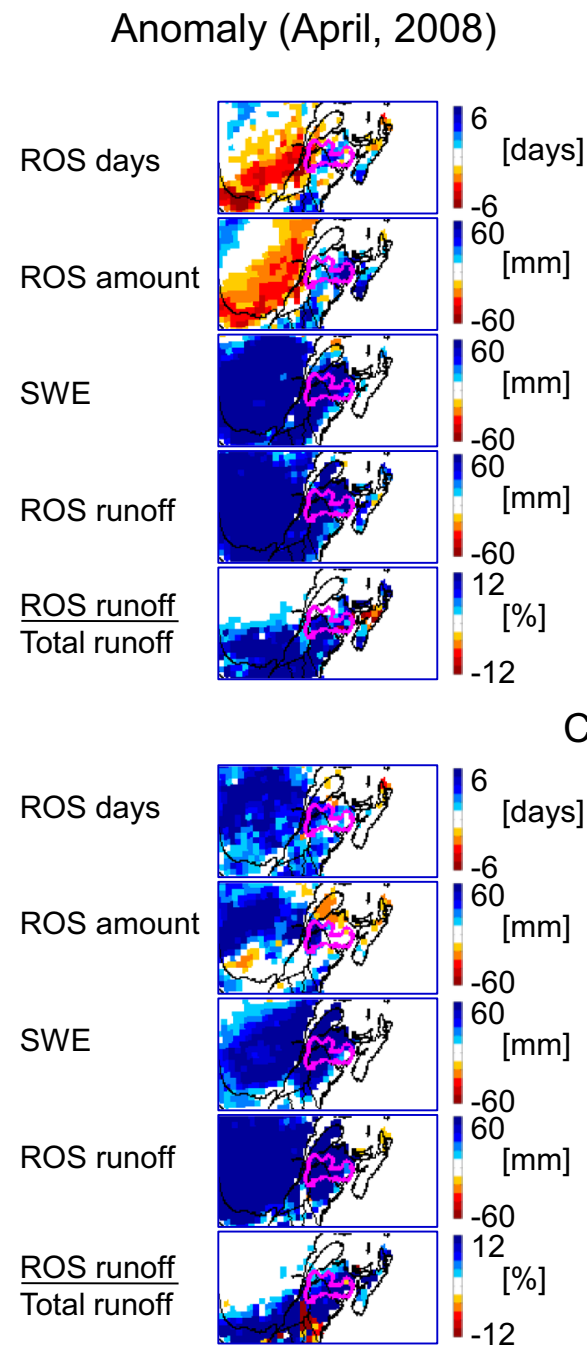

Time series (2008)

CRCM5-ERA

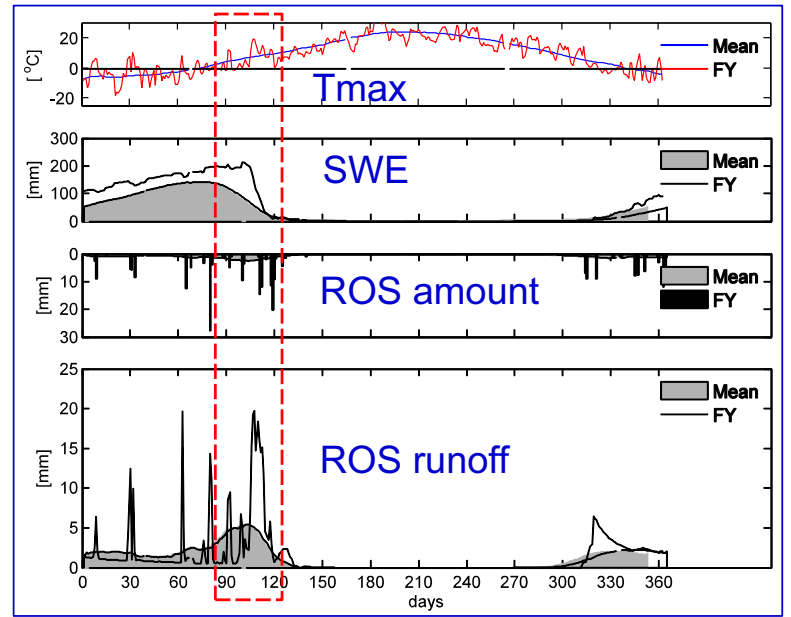

CanRCM4-ERA

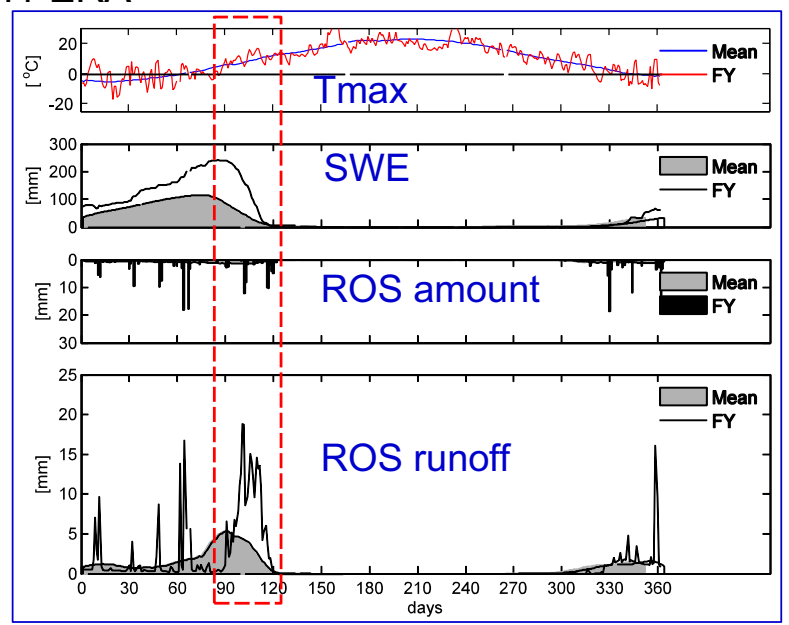

Fig. 2 a Location of the St-John and Red River basins. April 2008 anomalies of the ROS characteristics, SWE, and the ratio of ROS runoff to total runoff for the two ERA-Interim driven RCM simulations (i.e., CRCM5-ERA and CanRCM4-ERA) with respect to the 1989-2009 reference period for the St-John River basin are presented in the left column of (b), with the basin boundary shown in magenta.
Basin- averaged daily time series of max temperature (Tmax), SWE, and ROS amount and runoff for the reference period and the flood year $(F Y)$ are presented in the right column of $(\mathbf{b})$. $\mathbf{c}$ is similar to (b), but for Red River basin for March 2009. The red dashed boxes represent the flood periods considered, i.e., April for the St-John River basin and March for the Red River basin 


\section{(c) Red River basin}

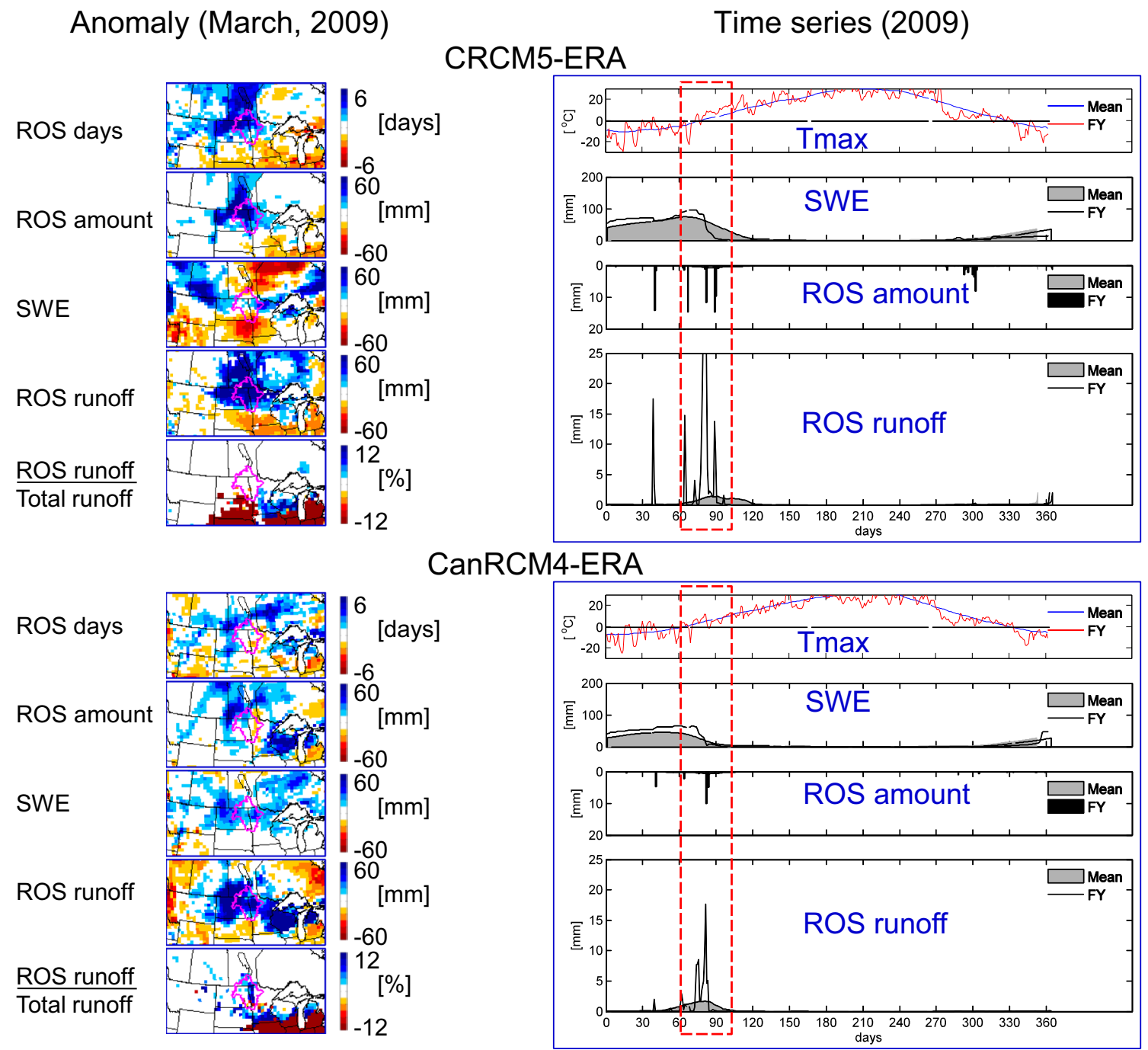

Fig. 2 (continued)

other variables during the flood month. For instance, only CRCM5-ERA yields above-normal ROS days and amount, while only CanRCM4-ERA exhibits above-normal SWE and the ratio of ROS runoff to total runoff. However, careful analysis of the daily time series shows that the sudden increase in temperature and subsequent ROS events that triggered rapid snowmelt are well captured by both RCMs. The above two cases suggest the ability of both models in reproducing ROS related flood events.

\subsection{Projected changes}

Figure 3 shows projected changes to monthly ROS days, amount, and runoff for CRCM5-MPIRCP8.5, CRCM5CanRCP8.5, and CanRCM4-CanRCP8.5. The three simulations generally show increases in the future ROS characteristics to the north of the future freezing line, particularly from November to May. This is due to future increases in rainfall frequency. These increases in the frequency and the areal extent of ROS events by the RCMs are broadly in agreement with the GCM-based studies of Putkonen and Roe (2003) and Rennert et al. (2009). The RCM simulations, however, show general decreases in the ROS characteristics to the south of the future freezing line, associated with decreases in snow cover. Future ROS runoff shows larger increases than future ROS rainfall during the month of March in some cases, as ROS events generally accelerate snowmelt and enhances ROS runoff. On the contrary, ROS amount is projected to increase more in the future than ROS runoff during the snow onset month of November, as the amount of snow on the ground is much smaller compared to the following months. Projected 


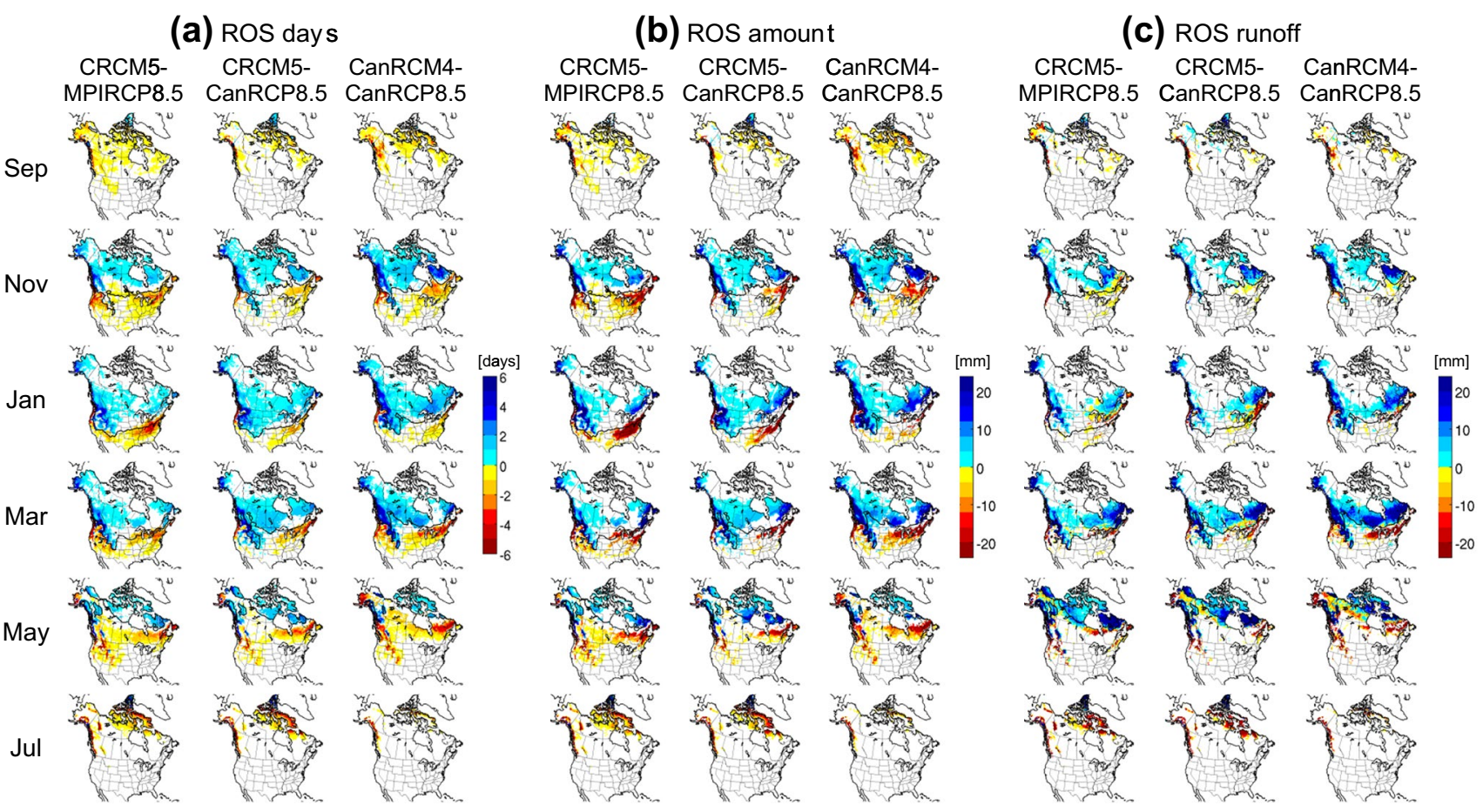

Fig. 3 Projected changes to (a) the number of ROS days, b ROS amount, and c ROS runoff for the three RCM simulations (i.e., CRCM5-MPIRCP8.5, CRCM5-CanRCP8.5, and CanRCM4-CanRCP8.5) for the future 2041-2070 period with respect to the current
1976-2005 period. The black contour represents the mean freezing line in future climate. Projected changes are shown when they are statistically significant with the two-sample $t$ test at the $10 \%$ significance level changes to the ROS characteristics show slightly different spatial distributions depending on the RCM and the driving GCM. For instance, CRCM5-MPIRCP8.5 broadly suggests smaller increases in magnitude and areal extent for the studied ROS characteristics compared to CRCM5CanRCP8.5, highlighting the differences in projections caused by the differences in the driving GCMs. It must be noted that CanESM2 projects higher increases in temperature compared to MPI-ESM (Šeparović et al. 2013). This would lead to higher rainfall occurrence frequency in CRCM5-CanRCP8.5 compared with CRCM5-MPIRCP8.5. On the other hand, CRCM5-CanRCP8.5 suggests broadly similar but regionally different projections compared to CanRCM4-CanRCP8.5, due to the differences in the physical parameterizations. Projected changes based on the three simulations for the RCP4.5 pathway generally suggest smaller increases/decreases than those for the RCP8.5 pathway for the future ROS characteristics, due to smaller increases of future air temperature and precipitation frequency and intensity (not shown).

Detailed regional-level analysis of changes to ROS characteristics for CRCM5-CanRCP4.5 is presented here. Figure 4 presents projected changes to the three ROS characteristics and their relevant climate components, i.e., number of snow covered days, rainfall day, precipitation intensity, and SWE, for CRCM5-CanRCP4.5 simulation for the month of April. Northern parts of North America and some regions of northwestern mountainous US show an increase in ROS days in the future due to increased air temperature and associated increase in rainfall days. The number of snow covered days in future climate is similar to that in current climate for these regions as air temperatures will be usually lower than the freezing point. However, most of the mid-latitude North American regions display a decrease in ROS days in the future, mainly due to increased air temperature and associated decrease in snow covered days (Fig. 4d, e). The northern part of North America and the mountainous northwestern US also show an increase in ROS amount in future due to an increase in ROS days as well as an increase in precipitation intensity (Fig. 4f). The mid-latitude North American regions, however, show a decrease in ROS amount, mainly due to a decrease in ROS days (Fig. 4a). Again, ROS runoff shows larger increases than ROS amount, particularly for northeastern North America, due to increases in the ROS amount and enhanced snowmelt generated runoff.

In Fig. 5, projected changes to the three ROS characteristics for the January-May months are presented for different elevation bands for two selected mountainous regions in northwestern US, for CRCM5-CanRCP8.5 simulation. Results show a general increase in the ROS characteristics for high elevation bands (i.e., higher than $1000 \mathrm{~m}$ ), and a 


\section{ROS characteristics}
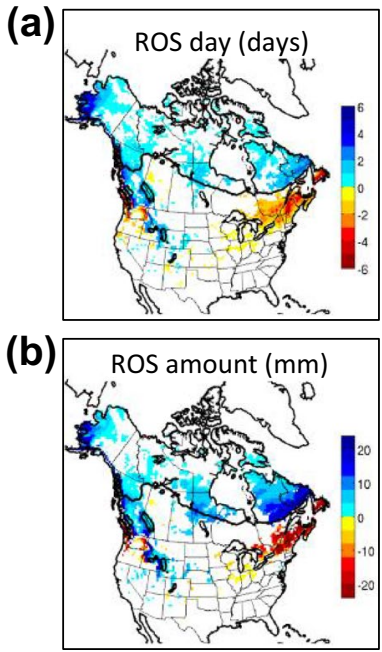

(c)

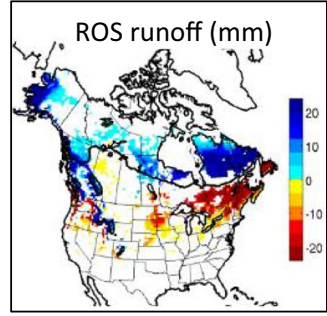

ROS-related hydro-climate variables

(d) Snow covered days (days)

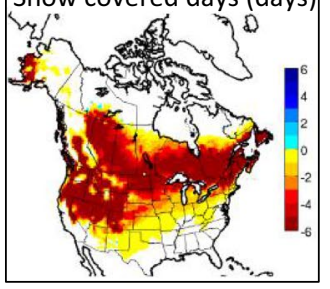

(e)

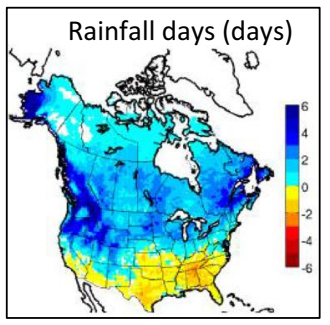

(f)

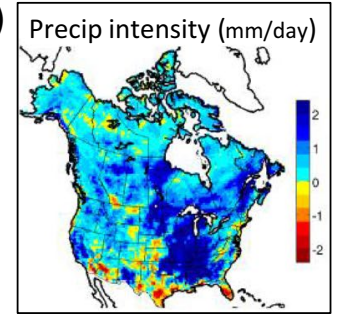

(g)

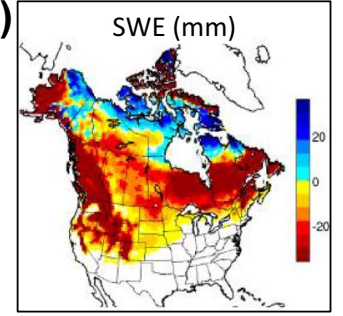

Fig. 4 Projected changes to ROS characteristics for the CRCM5CanRCP4.5 simulations for April for the 2041-2070 period with respect to the 1976-2005 period (left column). Projected changes to the number of snow covered days (i.e., days with SWE larger than $1 \mathrm{~mm}$ ), rainfall days (i.e., days with rainfall larger than $1 \mathrm{~mm}$ ), mean precipitation intensity, and SWE are also presented (right column). The black contour corresponds to the future freezing line (i.e., future Tmean is $0^{\circ} \mathrm{C}$ ). Projected changes are shown only for grid points with statistically significant changes, estimated by the two-sample $t$ test at the $10 \%$ significance level

decrease for the lowest elevation band (i.e., lower than $500 \mathrm{~m}$ ) for the two regions. These results are in good agreement with the results of McCabe et al. (2007), although their results were obtained based on site observations for the 1949-2003 period. ROS runoff generally shows smaller increases than ROS amount for the high elevation bands of the selected mountainous regions in the future, which is due to decreasing SWE in future climate.

The probability that the daily ROS runoff is the daily annual maximum runoff, for the January-May months,

for the current and future periods, is shown in Fig. 6, for RCP8.5 scenario. For the current period, the three simulations suggest that the probability is generally higher than $80 \%$ for most of Canada and for the northern parts of the US, indicating that ROS events is the primary flood generating mechanism for these regions during the snowmelt months. Over northeastern US, this result is in agreement with the findings of Pradhanang et al. (2013), that reported that the annual peak flows measured at 31 gaged watersheds distributed throughout the New York State for the 2003-2012 period were frequently induced by ROS events. For the future period, the three simulations suggest that this probability will decrease for the northeastern and northwestern US as well as southeastern Canada. However, results suggest that ROS events will continue to be a major maximum daily runoff generating mechanism for most parts of Canada and parts of the mountainous northwestern US for the January-May months in future climate.

Figure 7 presents projected changes to spatially averaged monthly climate variables and ROS runoff for St-John and Red River basins. For St-John River basin, the four CanESM2 driven simulations generally suggest an increase in future ROS and total runoff for January and February, while a decrease is noted for March and April for both RCP4.5 and RCP8.5 emission pathways. The two MPIESM driven simulations, however, project an increase/ decrease in future ROS and total runoff for slightly different months from those of CanESM2 driven simulations, i.e., an increase for January-March and a decrease for April and May, for both RCP4.5 and RCP8.5 emission pathways. The increase in future total runoff for winter is associated with increases in future rainfall and ROS runoff. On the other hand, the decrease in future total runoff for spring is associated with decreases in future SWE and/or early snowmelt and ROS runoff. For the Red River basin, the six simulations also suggest a decrease in future ROS runoff and total runoff for spring for both RCP4.5 and RCP8.5 emission pathways. The projected changes to monthly ROS runoff and total runoff for this basin are more consistent, compared to those of the St-John River basin during the snowmelt months, indicating the influence of ROS frequency changes on total runoff changes for the Red River basin is more significant than that for the St-John River basin. The six simulations suggest that both spring total runoff and ROS runoff will decrease for both river basins in the future. However, the magnitudes and timing of these decreases vary based on the RCM and driving GCM considered.

In summary, minimum, mean, and maximum projected changes to the three ROS characteristics for the January-May months for the future period with respect to the current period, based on the six future RCM-GCM simulations, are presented in Fig. 8. Projected changes to the number of ROS days show similar spatial patterns with those 


\section{Elevations and analysis regions $A$ and $B$}

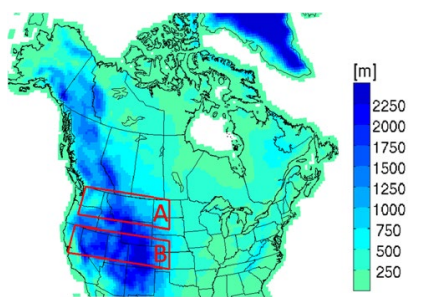

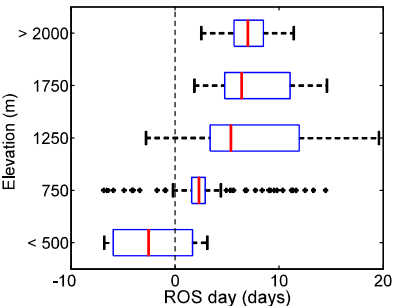

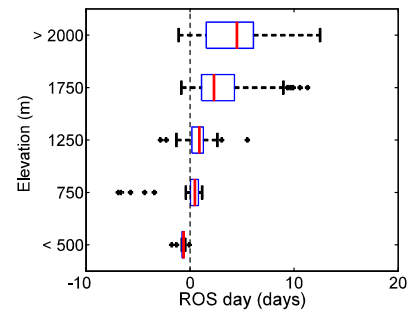

Fig. 5 Projected changes to ROS characteristics (i.e., ROS days, amount, and runoff) for the January-May months, for different elevation bands $(0-500,500-1000,1000-1500,1500-2000$, and greater than $2000 \mathrm{~m}$ ) at two selected mountainous western North American
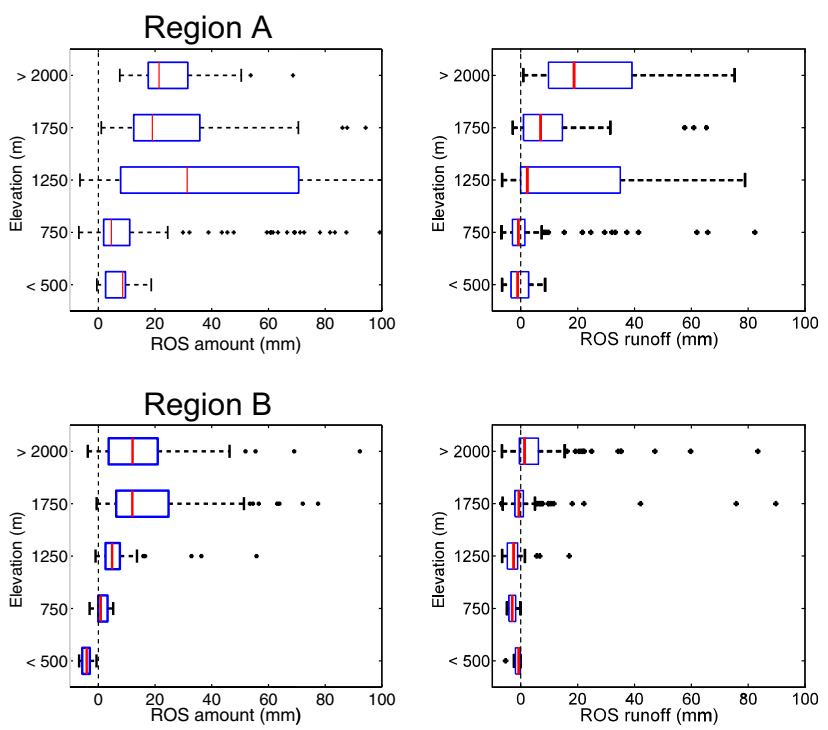

regions (1st column), base on CRCM5-CanHist and CRCM5-CanRCP8.5 simulations, for the future 2041-2070 period with respect to the current 1976-2005 period. Projected changes are presented by box and whisker plots
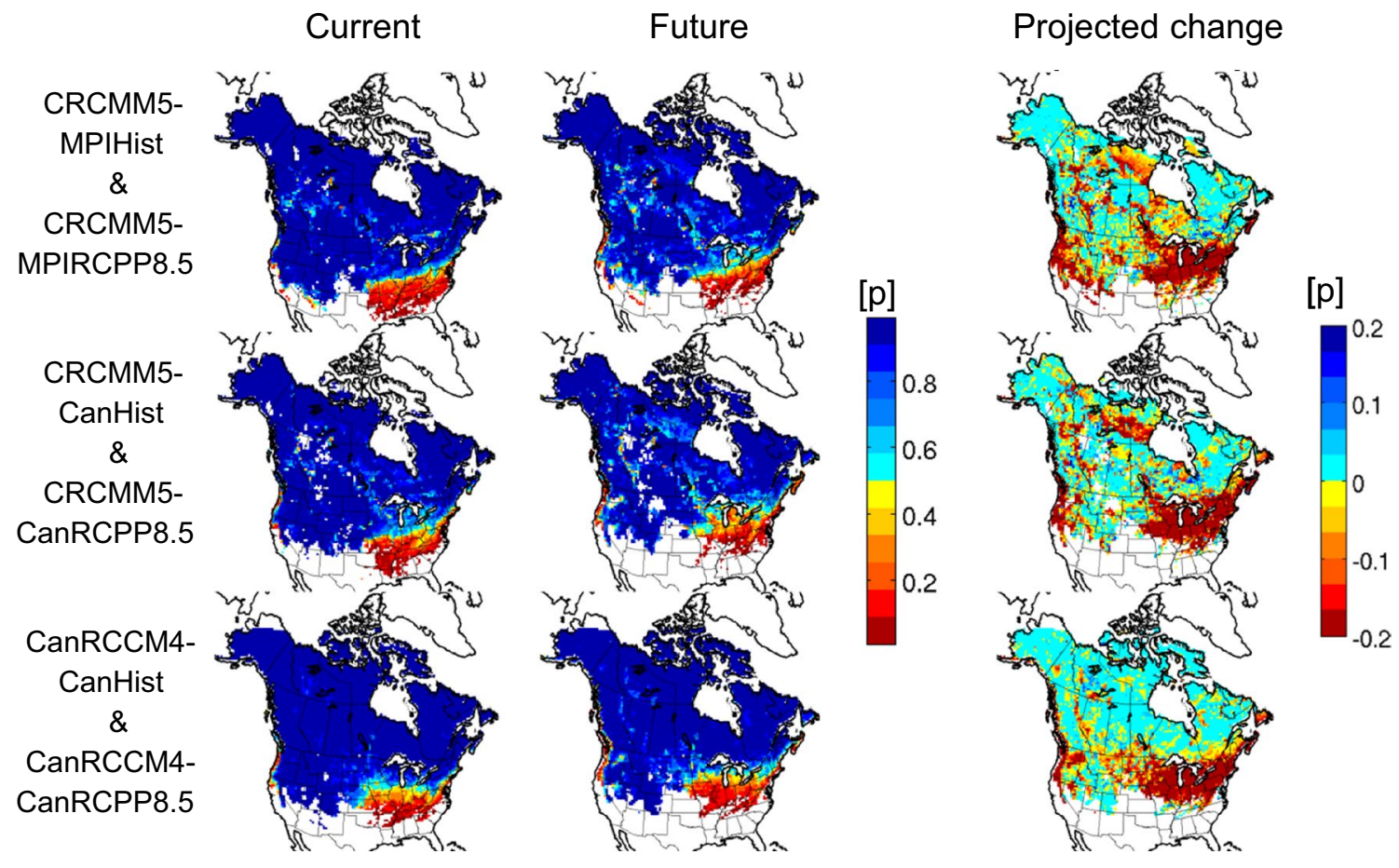

Fig. 6 The occurrence probability that the daily ROS runoff is the annual maximum daily runoff for the January-May period for the current 1976-2005 (left panel) and future 2041-2070 (middle panel)

of ROS amount. Again, general decreases in ROS runoff for the January-May period are projected for the southern parts of North America, due to the generally decreasing SWE in future climate for these regions and months. climates, based on simulations for the RCP8.5 pathway. Projected changes to the statistic for the future period with respect to the current period are shown in the right panel

Spatial patterns of projected changes to ROS runoff are also similar to those of ROS days and amount for the northern regions, but some differences can be noted for the southern regions. The range between maximum and minimum 
(a) St-John River Basin
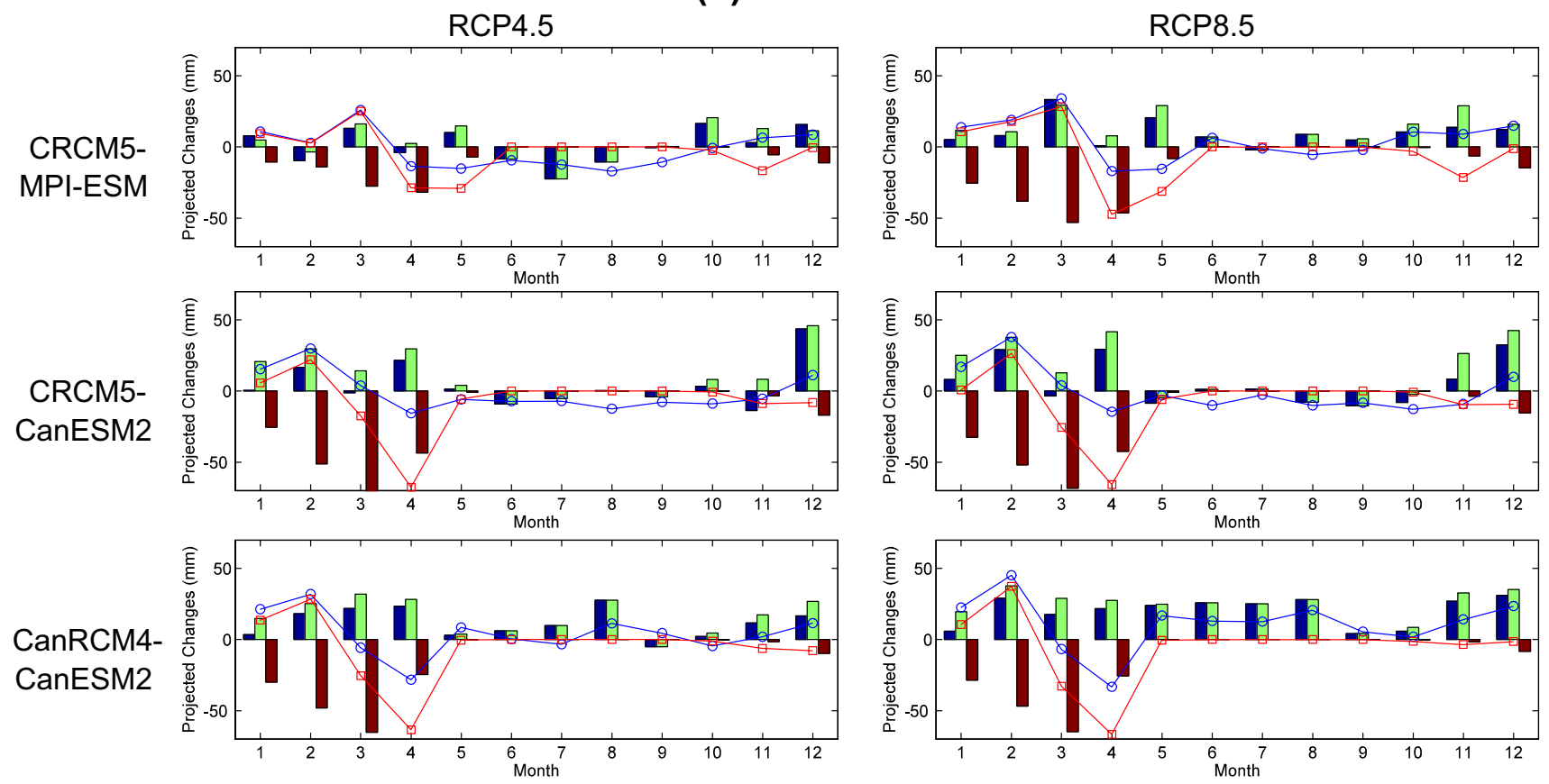

(b) Red River Basin

CRCM5-

MPI-ESM
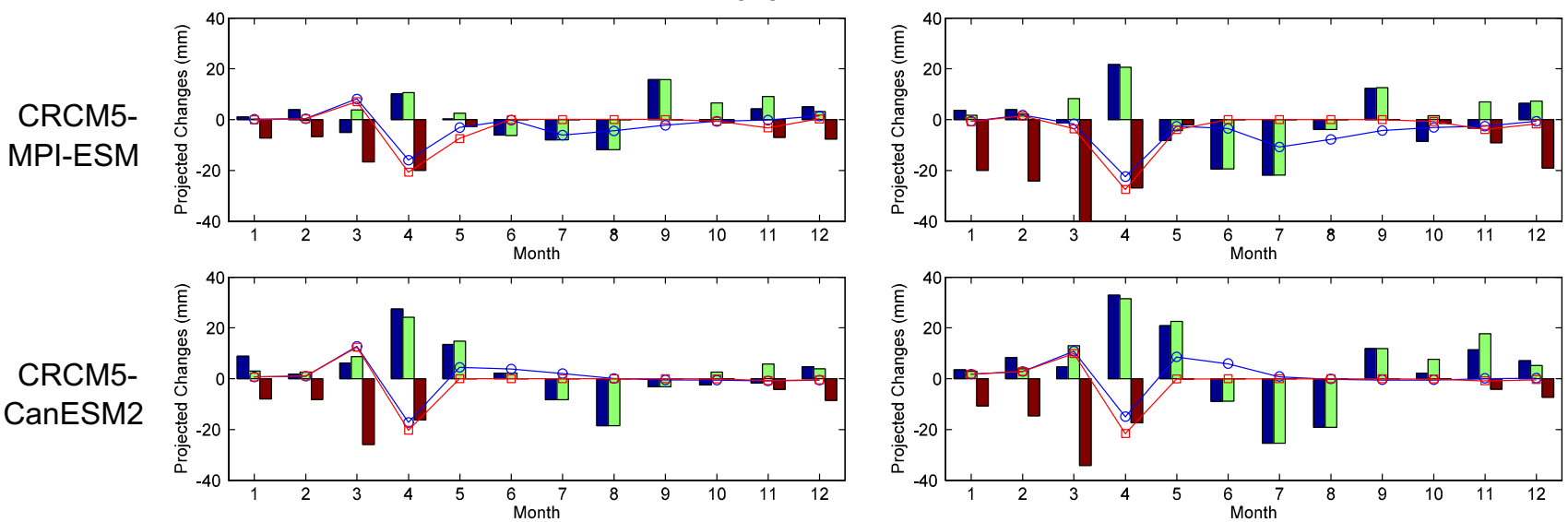

CanRCM4-
CanESM2
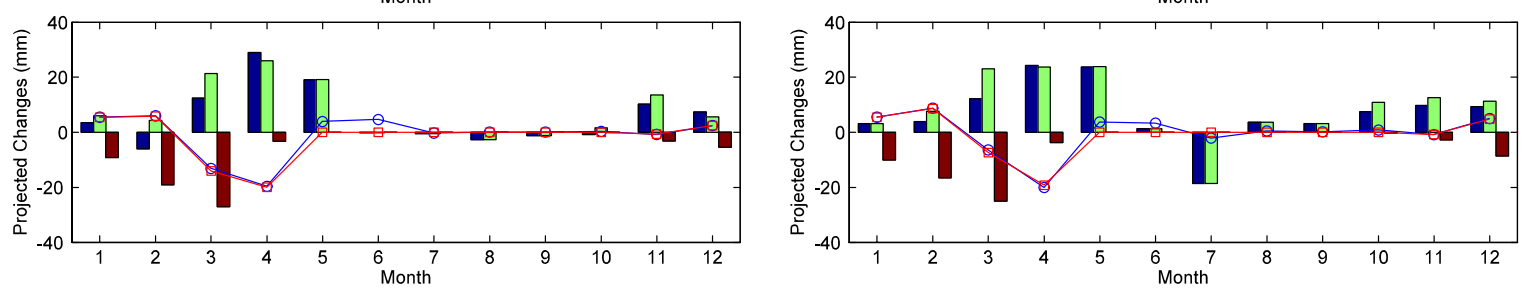

$\square$ Precp. $\square$ Rainfall $\square$ SWE

- Total Runoff $\quad$ - ROS Runoff

Fig. 7 Projected changes to the basin-averaged monthly climate variables (i.e., total precipitation, rainfall, SWE, total runoff and total ROS runoff) for a St-John and b Red River basins for the future
2041-2070 period with respect to the current 1976-2005 period, based on the six RCM-GCM simulations

eastern regions of North America. The zonally averaged values exhibit larger spreads in projected changes for ROS days and amount compared to ROS runoff. The zonally projected changes from the six combinations is an indication of the uncertainty in projections, which are generally larger for the western and central regions compared to the 

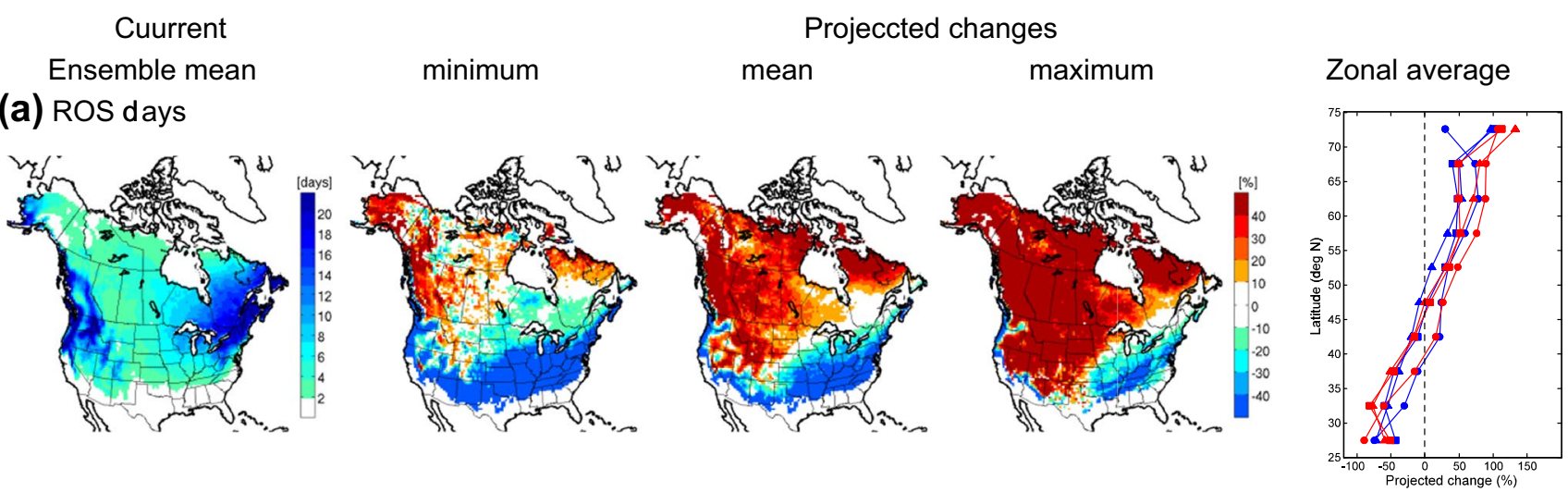

(b) ROS amount
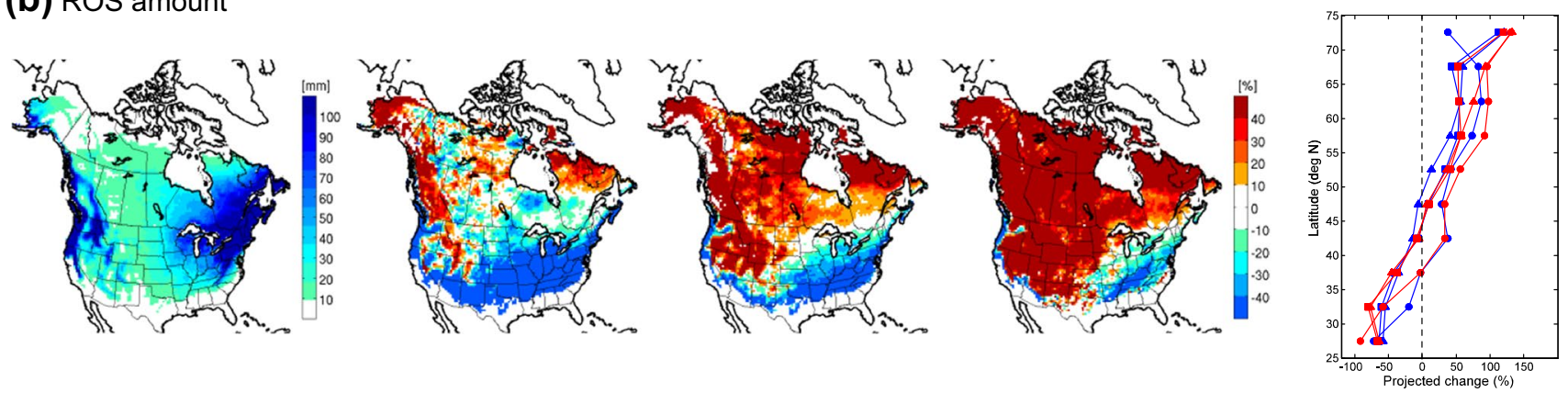

(c) ROS runoff
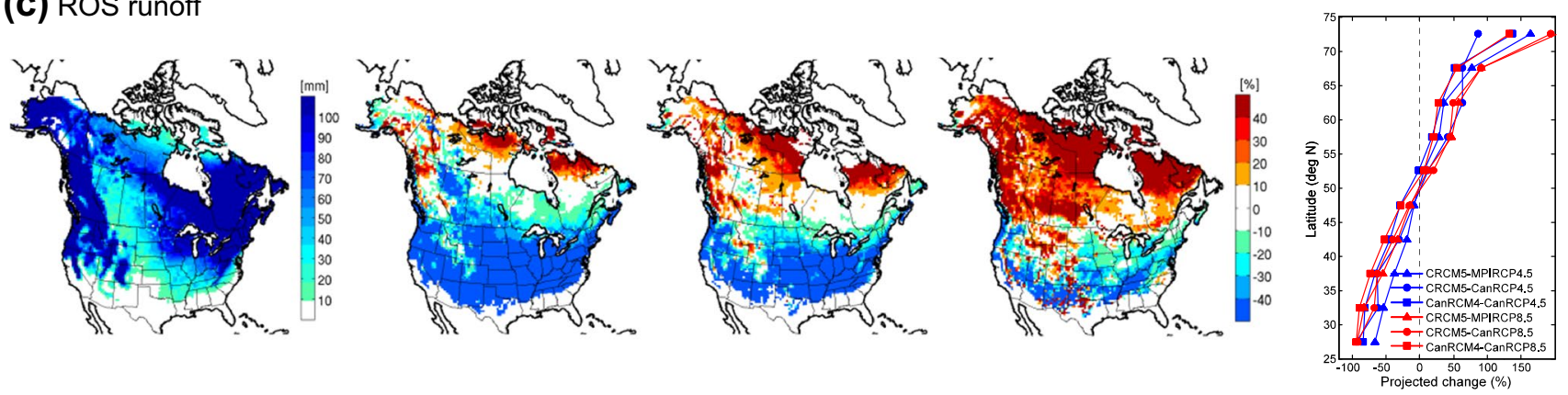

Fig. 8 Ensemble averaged values of three ROS characteristics for the January-May months for the current (1976-2005) period (first column) and minimum, mean, and maximum projected changes (\%) to the characteristics for the future (2041-2070) period (second-forth

averaged values also suggest that the projected increases for the northern parts for RCP 8.5 are larger than those for RCP 4.5 , while the projected decreases for the southern regions are larger for RCP 8.5 compared to those for RCP 4.5.

\section{Summary and conclusions}

Projected changes to rain-on-snow (ROS) characteristics (i.e., frequency, rainfall amount, and runoff) over North America for the future 2041-2070 period, using two Canadian RCMs, are investigated in this paper. Evaluation of ERA-Interim driven RCM simulations indicates that the RCMs are able to reproduce observed spatial patterns of columns), based on the three current and six future RCM-GCM simulations, respectively. Zonally averaged values of projected changes to the three characteristics are also shown in fifth column

ROS event frequency. The RCMs also simulate reasonably the general hydro-meteorological mechanisms of spring flood events induced by ROS events, such as $2 \mathrm{~m}$ air temperature variability, accumulation of winter and spring SWE, heavy ROS events, and associated runoff response.

Six simulations based on the two RCMs, driven by two driving GCMs for RCP4.5 and 8.5 emission pathways, suggest general increases in the future ROS characteristics to the north of the future freezing line due to increases in rainfall frequency with increased air temperature. On the contrary, they suggest general decreases in future ROS characteristics to the south of the future freezing line due to decreases in SWE and snow cover frequency in future climate. Consequently, the six simulations generally suggest 
increases in future ROS characteristics during the November to March period for most regions of Canada and northwestern US. Future ROS runoff tends to increase more than ROS amount during snowmelt months as ROS events can accelerate snowmelt and enhance ROS runoff. Based on the RCMs and driving GCMs considered in this study, the projections appear to be more sensitive to the driving GCM than to the RCM. It must be noted that the two RCMs considered in this study are similar with respect to dynamical core and selected parameterizations.

The simulations illustrate that ROS events is a major flood generating mechanism, with maximum daily runoff being associated with ROS events $80 \%$ of the time, for most of Canada and north-western and -central parts of the US during the January-May months for both current and future climates. Assessments over St-John and Red River basins suggest an increase in future runoff for winter and/or early spring due to an increase in rainfall and ROS runoff, whereas a decrease in future spring runoff due to decreases in SWE and ROS runoff. However, more detailed studies are necessary to assess future occurrences of extreme compound events arising from extreme SWE and ROS amounts, leading to extreme flood events.

The projected changes to the ROS characteristics derived in this study, based on the high-resolution RCMs, will be useful to evaluate detailed regional impacts on different social, environment, and ecosystem sectors over North America. Though the results based on the two Canadian RCMs agree overall, a broader set of simulations including other RCMs and driving GCMs might be useful to properly evaluate uncertainties in the future projections.

Acknowledgements We wish to thank the Canadian Centre for Climate Modelling and Analysis (CCCma) of Environment and Climate Change Canada for providing the CanRCM4 data used in this paper. This research was undertaken within the framework of the Canadian Network for Regional Climate and Weather Processes, funded through the NSERC-CCAR (Natural Sciences and Engineering Research Council-Climate Change and Atmosphere Research) program.

Open Access This article is distributed under the terms of the Creative Commons Attribution 4.0 International License (http:// creativecommons.org/licenses/by/4.0/), which permits unrestricted use, distribution, and reproduction in any medium, provided you give appropriate credit to the original author(s) and the source, provide a link to the Creative Commons license, and indicate if changes were made.

\section{References}

Arora VK, Scinocca JF, Boer GJ, Christian JR, Denman KL, Flato GM, Kharin VV, Lee WG, Merryfield WJ (2011) Carbon emission limits required to satisfy future representative concentration pathways of greenhouse gases. Geophys Res Lett 38:L05805. doi :10.1029/2010GL046270
Barker HW, Cole JNS, Morcrette J-J, Pincus R, Räisänen P, von Salzen K, Vaillancourt PA (2008) The Monte Carlo independent column approximation: an assessment using several global atmospheric models. Q J R Meteorolog Soc 134:1463-1478

Bélair S, Mailhot J, Girard C, Vaillancourt P (2005) Boundary layer and shallow cumulus clouds in a medium-range forecast of a large-scale weather system. Mon Weather Rev 133(7):1938-1960

Bourgouin P (2000) A method to determine precipitation types. Weather Forecast 15(5):583-592

Brown RD, Brasnett B, Robison D (2003) Gridded North American monthly snow depth and snow water equivalent for GCM evaluation. Atmos Ocean 41:1-14

Casson NJ, Eimers MC, Buttle JM (2010) The contribution of rain-onsnow events to nitrate export in the forested landscape of southcentral Ontario, Canada. Hydrol Process 24(14):1985-1993

Côté J, Gravel S, Méthot A, Patoine A, Roch M, Staniforth A (1998) The operational CMC-MRB global environmental multiscale (GEM) model. Part I: design considerations and formulation. Mon Weather Rev 126(6):1373-1395

Dee DP, Uppala SM, Simmons AJ, Berrisford P, Poli P, Kobayashi S, Andrae U, Balmaseda MA, Balsamo G, Bauer P, Bechtold P, Beljaars ACM, van de Berg L, Bidlot J, Bormann N, Delsol C, Dragani R, Fuentes M, Geer AJ, Haimberger L, Healy SB, Hersbach H, Hólm EV, Isaksen L, Kållberg P, Köhler M, Matricardi M, McNally AP, Monge-Sanz BM, Morcrette J-J, Park B-K, Peubey C, de Rosnay P, Tavolato C, Thépaut J-N, Vitart F (2011) The ERA-interim reanalysis: configuration and performance of the data assimilation system. Q J R Meteorolog Soc 137:553-597

Diro GT, Sushama L, Martynov A, Jeong DI, Verseghy D, Winger K (2014) Land-atmosphere coupling over North America in the CRCM5. J Geophys Res. doi:10.1002/2014JD021677

Environment Canada (2008) Canada's Top Ten Weather Stories for 2008. https://ec.gc.ca/meteo-weather/default. asp?lang $=$ En\&n $=3 \mathrm{E} 8 \mathrm{FBA} 3 \mathrm{~F}-1$

Environment Canada (2009) Canada's Top Ten Weather Stories for 2009. https://ec.gc.ca/meteo-weather/default. asp?lang $=$ En\&n $=645$ A8F9C -1

Floyd W, Weiler M (2008) Measuring snow accumulation and ablation dynamics during rain-on-snow events: innovative measurement techniques. Hydrol Process 22(24):4805-4812

Freudiger D, Kohn I, Stahl K, Weiler M (2014) Large-scale analysis of changing frequencies of rain-on-snow events with flood-generation potential. Hydrol Earth Syst Sci 18(7):2695-2709

Giorgetta MA et al (2013) Climate and carbon cycle changes from 1850 to 2100 in MPI-ESM simulations for the Coupled Model Intercomparison Project phase 5. J Adv Model Earth Syst 5:572-597

Hopkinson RF, McKenney DW, Milewska EJ, Hutchinson MF, Papadopol P, Vincent LA (2011) Impact of aligning climatological day on gridding daily maximum-minimum temperature and precipitation over Canada. J Appl Meteorol Climatol 50(8):1654-1665

Hutchinson MF, McKenney DW, Lawrence K, Pedlar JH, Hopkinson RF, Milewska E, Papadopol P (2009) Development and testing of Canada-wide interpolated spatial models of daily minimummaximum temperature and precipitation for 1961-2003. J Appl Meteorol Climatol 48(4):725-741

IPCC (2001) In: Houghton JT, Ding Y, Griggs DJ, Noguer M, van der Linder PJ, Dai X, Maskell K, Johnson CA (eds), Climate change 2001: the scientific basis. Cambridge University Press, 881

Jeong DI, Sushama L, Khaliq MN (2014a) The role of temperature in drought projections over North America. Clim Change 127:289303. doi:10.1007/s10584-014-1248-3

Jeong DI, Sushama L, Khaliq MN, Roy R (2014b) A copula-based multivariate analysis of Canadian RCM projected changes 
to flood characteristics for northeastern Canada. Clim Dyn 42:2045-2066

Jeong DI, Sushama L, Diro GT, Khaliq MN (2016a) Projected changes to winter temperature characteristics over Canada based on an RCM ensemble. Clim Dyn 47(5):1351-1366

Jeong DI, Sushama L, Diro GT, Khaliq MN, Beltrami H, Caya D (2016b) Projected changes to high temperature events for Canada based on a regional climate model ensemble. Clim Dyn 46:3163-3180

Jeong DI, Sushama L, Khaliq MN (2016c) Attribution of spring snow water equivalent (SWE) changes over the northern hemisphere to anthropogenic effects. Clim Dyn. doi:10.1007/ s00382-016-3291-4

Kain J, Fritsch J (1992) The role of the convective trigger function in numerical forecasts of mesoscale convective systems. Meteorol Atmos Phys 49(1-4):93-106

Leathers DJ, Kluck DR, Kroczynski S (1998) The severe flooding event of January 1996 across north-central Pennsylvania. Bull Am Meteorol Soc 79(5):785-797

Li J, Barker H (2005) A radiation algorithm with correlated-k distribution. Part I: local thermal equilibrium. J Atmos Sci 62(2):286-309

Marks D, Kimball J, Tingey D, Link T (1998) The sensitivity of snowmelt processes to climate conditions and forest cover during rain-on-snow: a case study of the 1996 Pacific Northwest flood. Hydrol Process 12:1569-1587

Martynov A, Sushama L, Laprise R, Winger K, Dugas B (2012) Interactive lakes in the Canadian regional climate model, version 5: the role of lakes in the regional climate of North America. Tellus A 64:16226-16245. doi:10.3402/tellusa.v64i0.16226

Maurer E, Wood A, Adam J, Lettenmaier D, Nijssen B (2002) A long-term hydrologically based dataset of land surface fluxes and states for the conterminous United States. J Clim 15(22):3237-3251

McCabe GJ, Hay LE, Clark MP (2007) Rain-on-snow events in the western United States. Bull Am Meteorol Soc 88(3):319-328

Nied M, Pardowitz T, Nissen K, Ulbrich U, Hundecha Y, Merz B (2014) On the relationship between hydro-meteorological patterns and flood types. J Hydrol 519:3249-3262

Pincus R, Barker HW, Morcrette J-J (2003) A fast, flexible, approximate technique for computing radiative transfer in inhomogeneous cloud fields. J Geophys Res Atmos 108(D13) doi:10.1029/2 002JD003322

Pradhanang SM, Frei A, Zion M, Schneiderman EM, Steenhuis TS, Pierson D (2013) Rain-on-snow runoff events in New York. Hydrol Process 27(21):3035-3049
Putkonen J, Roe G (2003) Rain-on-snow events impact soil temperatures and affect ungulate survival. Geophys Res Lett 30(4) doi:10 .1029/2002GL016326

Putkonen J, Grenfell TC, Rennert K, Bitz C, Jacobson P, Russell D (2009) Rain on snow: little understood killer in the north. Eos Trans Am Geophys Union 90(26):221-222.

Rennert KJ, Roe G, Putkonen J, Bitz CM (2009) Soil thermal and ecological impacts of rain on snow events in the circumpolar Arctic. J Clim 22(9):2302-2315

Šeparović L, Alexandru A, Laprise R, Martynov A, Sushama L, Winger K, Tete K, Valin M (2013) Present climate and climate change over North America as simulated by the fifth-generation Canadian regional climate model. Clim Dyn 41:3167-3201

Sui J, Koehler G (2001) Rain-on-snow induced flood events in Southern Germany. J Hydrol 252(1):205-220

Sundqvist H, Berge E, Kristjánsson JE (1989) Condensation and cloud parameterization studies with a mesoscale numerical weather prediction model. Mon Weather Rev 117(8):1641-1657

Surfleet CG, Tullos D (2013) Variability in effect of climate change on rain-on-snow peak flow events in a temperate climate. $\mathrm{J}$ Hydrol 479:24-34

Verseghy D (2009) CLASS the Canadian land surface scheme (version 3.4), tech. Rep Clim Res Divi Sci Technol Branch Environ Can 107

Verseghy D (2012) CLASS-the Canadian land surface scheme (version 3.6). Environ Can Sci Technol Branch Tech Rep 179

von Salzen K, McFarlane NA (2002) Parameterization of the bulk effects of lateral and cloud-top entrainment in transient shallow cumulus clouds. J Atmos Sci 59:1405-1429

von Salzen K, McFarlane NA, Lazare M (2005) The role of shallow convection in the water and energy cycles of the atmosphere. Clim Dyn 25:671-688

von Salzen K, Scinocca JF, McFarlane NA, Li J, Cole JNS, Plummer D, Reader MC, Ma X, Lazare M, Solheim L (2013) The Canadian fourth generation atmospheric global climate model (CanAM4). Part I: representation of physical processes. Atmos Ocean 51(1):104-125. doi:10.1080/07055900.2012.755610

Whan K, Zwiers F (2016) Evaluation of extreme rainfall and temperature over North America in CanRCM4 and CRCM5. Clim Dyn 46(11):3821-3843

Ye H, Yang D, Robinson D (2008) Winter rain on snow and its association with air temperature in northern Eurasia. Hydrol Process 22(15):2728-2736

Zhang GJ, McFarlane NA (1995) Sensitivity of climate simulations to the parameterization of cumulus convection in the CCC-GCM. Atmos Ocean 3:407-446 